\title{
Fish as Indicators for Environmental Monitoring and Health Risk Assessment Regarding Aquatic Contamination with Pesticides
}

\section{Yancheva $\mathrm{V}^{*}$, Stoyanova S, Velcheva I and Georgieva E}

Faculty of Biology, Plovdiv University, Bulgaria

*Corresponding author: Vesela Yancheva, Faculty of Biology, Plovdiv University, Tsar Assen Str. 24, 4000, Tel: 0035932261540; Email: veselayancheva@yahoo.com

\section{Mini Review}

Volume 3 Issue 1

Received Date: February 13, 2020

Published Date: February 21, 2020

DOI: $10.23880 /$ izab-16000210

\section{Abstract}

The proximity of water basins to anthropogenic sources of pollution affecting the state of nature also determines the need to study the ecosystems existing there. Fish are used as reliable indicators of pollution of the aquatic environment. Changes in the fish body make it possible to determine the toxicity of the contaminated water and the potential danger posed by anthropogenic substances that have entered it. In this regards, biomarkers are important assessment tools as they provide specific information on the biological effects of a particular toxicant. They can be used for monitoring purposes, as well as to clarify the link between the effects on the organism and the concentration of the contaminant in health risk assessment.

Keywords: Fish; Water Contamination; Organic Chemicals; Biomarkers

Abbreviations: ALAT: Alanine Aminotransferase; ASAT: Aspartate Aminotransferase; LDH: Lactate Dehydrogenase; CAT: Catalase; GR: Gutathione Reductase; GPx; Gutathione Peroxidase; SOD: Superoxide Dismutase; ChE: Cholinesterase.

\section{Introduction}

\section{Contamination of Aquatic Ecosystems with Organic Pollutants-Pesticides}

The development of the anthropogenic factor leads to an inevitable disturbance of the balance in aquatic ecosystems. Environmental pollution is the introduction into the environment of new, uncharacteristic substances or exceeding the level of their normal average annual concentration. Water pollutants can also be divided into natural (volcanic eruptions, dead plant or animal remains, etc) or man-made. The latter or chemical contaminants include POPs (persistent organic pollutants) as well as various types of pesticides. POPs are organic substances that have toxic properties; they remain in the environment for a long time; accumulate in the biosphere; they are capable of trans boundary long-range atmospheric transport and deposition; and are likely to have significant negative effects on human health or the environment near and far from their sources.

Pesticides are easily applicable, effective and are a basic practical tool in agriculture and plant protection. By definition, they are poisonous chemicals created by humans to control pests. Based on their chemical nature pesticides are divided into organophosphorus, organochlorine, carbamate, pyrethroid, neonicotinoid and others. Organophosphorous pesticides are one of the most commonly applied, but also dangerous to human health pesticides. They are developed because organochlorine pesticides, such as DDT are already banned. Organophosphorous pesticides have few advantages as they do not accumulate in the environment and have strong insecticidal activity. As a disadvantage we can note their solubility in biological media. In addition, the pesticide is rapidly metabolized in the organism and subsequently transformed into highly toxic metabolites that can damage also the human's body to varying degrees. 


\section{Biological Tools in Environmental Monitoring and Health Risk Assessment}

According to De Castilhos Ghisi, [1] it is important to evaluate the effect of pesticides in response to lower trophic levels before they affect higher trophic levels or the entire ecosystem. Changes in the body's molecular, cellular and tissue levels are used to evaluate the effects of organic pollutants.

Morphological change in cellular and tissue structure is an important parameter. Through the use of morphological methods, the most affected target organs can be identified, and the sensitivity of the organism to the level of toxicity at which it is exposed can be estimated. Histological methods allow differentiation of morphological changes; thus they can be used as tissue-level biomarkers [2]. Furthermore, histochemical techniques help to prove the localization of proteins, lipids, and glycogen at the cellular level; hence the main advantage of applying such techniques is the analysis of biological phenomena in "individual cells". In addition, the staining intensity can be used to compare proteins, lipids, or glycogen content in liver cells of control groups with experimental groups using different concentrations of toxicants [3].

Peebua, et al. [4] and Costa, et al. [5] propose to use semi-quantitative approaches to determine the extent of histologic changes that enable them to be objectively assessed in order to determine histological changes that have occurred. Moreover, according to Bernet, et al. [2] another criterion for histological studies relates to the actual biological significance of the histological alterations analyzed. This determines the importance of determining histologic changes that are different in different organs.
Biochemical alterations are also considered as reliable biomarkers for assessing aquatic ecosystem pollution. Biochemical changes are an important tool for detecting changes in the metabolism of exposed to pollutants in laboratory or field studies. They are a diagnostic index of the impact of pollutants. Through them, we can detect changes in the levels and activity of enzymes as an indicator of the effects of toxicants. The change in the activity of some antioxidant enzymes depends on the time of exposure, applied concentrations and species. In addition, the change in the enzyme activity can prove oxidative stress, which has been used as a marker in toxicological studies.

\section{Fish as a Major Test Organism in Environmental Monitoring and Health Risk Assessment}

Fish are extremely important in aquaculture as major protein source for humans. However, they are also major test organism in the field of aquatic toxicology. The reason for this is that they are very sensitive; they occupy different trophic levels, have large size and can be of different age. In this regards, fish gills are effective bio monitoring tools for investigating the effects of toxicants. They are a multifunctional organ with a large surface area (breathing, ionic regulation, maintenance of acid-base balance and excretion of nitrogen wastes), which is in constant contact with water [6]. Fish liver is another organ, which is studied in terms of aquatic contamination. Its functions are linked with regulation of the metabolism; synthesis of plasma proteins; energy storage in the form of lipids and vitamins, as well as detoxification of different toxicants [7].

Furthermore, changes in the liver enzyme activity levels can be used as reliable biomarkers for contaminated water [8]. In this regards, biochemistry is one of the fastest developing areas in ecological monitoring of aquatic ecosystems.

\section{Biochemical alterations in fish liver}

\begin{tabular}{|c|c|}
\hline \multicolumn{2}{|c|}{ Biochemical alterations in fish liver } \\
\hline \multicolumn{2}{|c|}{ Biomarker-Enzymes } \\
\hline Alanine aminotransferase (ALAT) & $\begin{array}{c}\text { participate in the glucose-alanine cycle in the liver, indica- } \\
\text { tor for impaired energy metabolism }\end{array}$ \\
\hline Aspartate aminotransferase (ASAT) & indicator for tissue damage, hepatotoxicity \\
\hline Lactate dehydrogenase (LDH) & $\begin{array}{c}\text { participates in the anaerobic pathway of energy } \\
\text { production; indicator of tissue damage }\end{array}$ \\
\hline \multicolumn{2}{|c|}{ Biomarkers-Antioxidant enzymes } \\
\hline $\begin{array}{l}\text { Catalase (CAT), Gutathione reductase (GR), Gutathione } \\
\text { peroxidase (GPx), Superoxide dismutase (SOD), }\end{array}$ & increased enzyme activity, indicator for oxidative stress \\
\hline Cholinesterase (ChE) & $\begin{array}{l}\text { reduction of enzyme activity, indicator for } \\
\text { organophosphorus poisoning }\end{array}$ \\
\hline
\end{tabular}

Table 1: Enzymatic biomarkers in fish. 
According to published data from Stoyanova, et al. [9], Yancheva, et al. [10], Stoyanova, et al. [11], the effects of pesticides on fish is expressed on the one hand in changing the histological structure of target organs, such as gills and liver. Histopathological disorders include proliferative and degenerative alterations, as well as those in the circulatory system of the organ. Depending on the concentrations applied and the type of pesticide, these disorders appear to varying degrees. According to the authors, proliferative disorders can be considered as compensatory-adaptive mechanisms that limit the entry of the toxicant. In addition, the authors found that higher concentrations cause degenerative disorders such as necrosis, as well as changes in the organ's blood system.
In addition, according to Georgieva, et al. [12], Stoyanova, et al. [13], Yancheva, et al. [10] the toxic effect of pesticides also causes changes in the liver morphology. They can be expressed in degenerative disorders such as granular, vacuolar and fatty degeneration, as well as necrosis and necrobiosis. The toxic effect of pesticides also affects the circulatory organ system, which is expressed in hyperemia and lymphocytic proliferation. Moreover, by applying histochemical methods Georgieva, et al. [14], Stoyanova, et al. [15], Yancheva, et al. [16], Stoyanova, et al. [17] found changes in the amount of liver glycogen, as well as a different degree of lipid accumulation in hepatocytes. These alterations prove disturbances in the processes of glycolysis and glyconeogenesis on the one hand, as well as processes of fatty degeneration on the other hand.

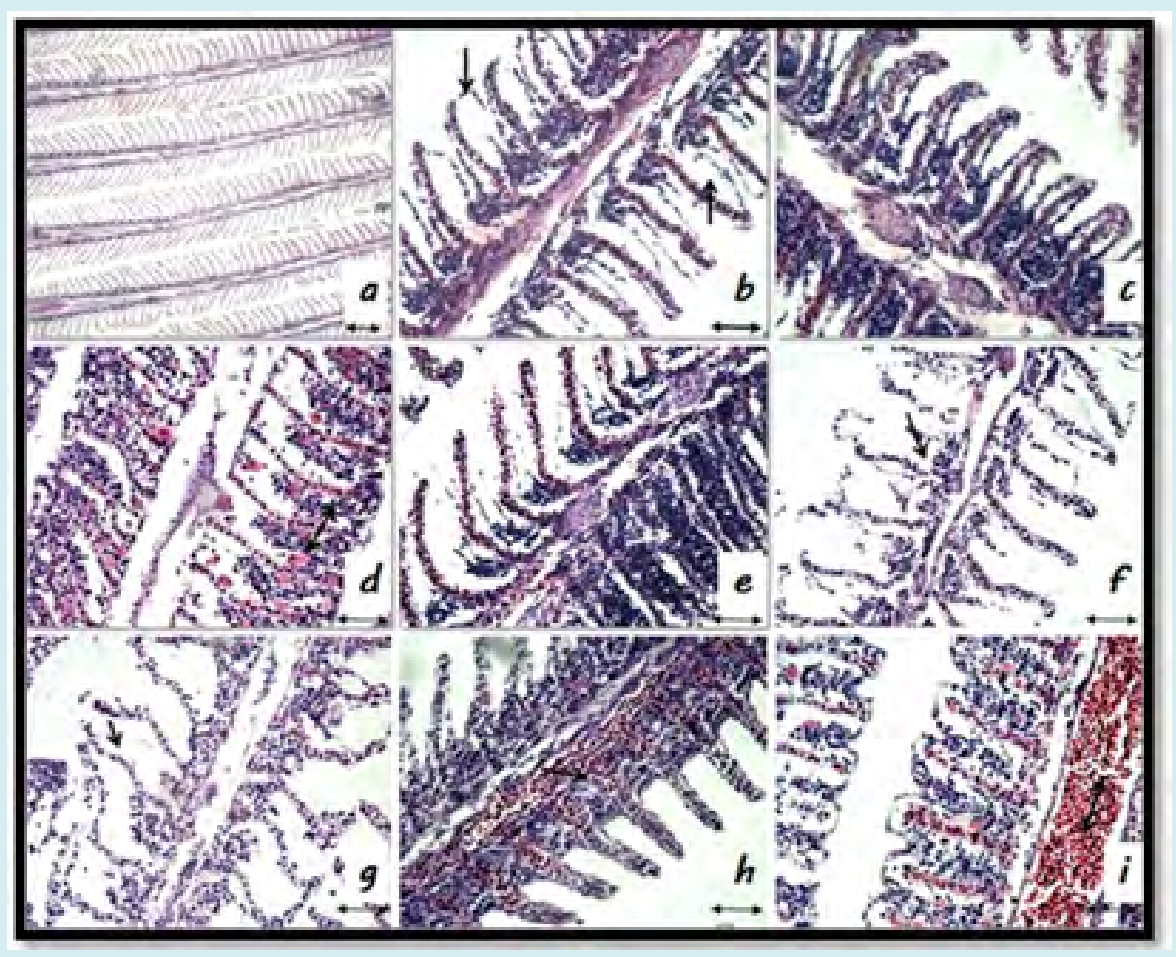

Figure 1: Histological biomarkers in gills of Cyprinus carpio L. under the action of thiamethoxam, H\&E [18]. a: Normal histological structure, $\mathrm{x} 200$

b: Lamellar lifting at a concentration of $6.6 \mathrm{mg} / \mathrm{L}$ thiamethoxam, $\mathrm{x} 400$

c: Edema at a concentration of $6.6 \mathrm{mg} / \mathrm{L}$ thiamethoxam, $400 \mathrm{x}$

$\mathrm{d}$ : Proliferation of glandular cells and epithelium at a concentration of $10 \mathrm{mg} / \mathrm{L}$ thiamethoxam, $\mathrm{x} 400$

e: Fusion of secondary lamellae at a concentration of $20 \mathrm{mg} / \mathrm{L}$ thiamethoxam, $\mathrm{x} 400$

$\mathrm{f}$ : Degeneration of the covering epithelium at a concentration of $10 \mathrm{mg} / \mathrm{L}$ thiamethoxam, $\mathrm{x} 400$

g: Degeneration of secondary lamellae at a concentration of $10 \mathrm{mg} / \mathrm{L}$ thiamethoxam, $\mathrm{x} 400$

$\mathrm{h}$ : Vasodilation in the secondary lamellae at a concentration of $6.6 \mathrm{mg} / \mathrm{L}$ thiamethoxam, $\mathrm{x} 400$

i: Vasodilation of the underlying sinus at a concentration of $6.6 \mathrm{mg} / \mathrm{L}$ thiamethoxam 


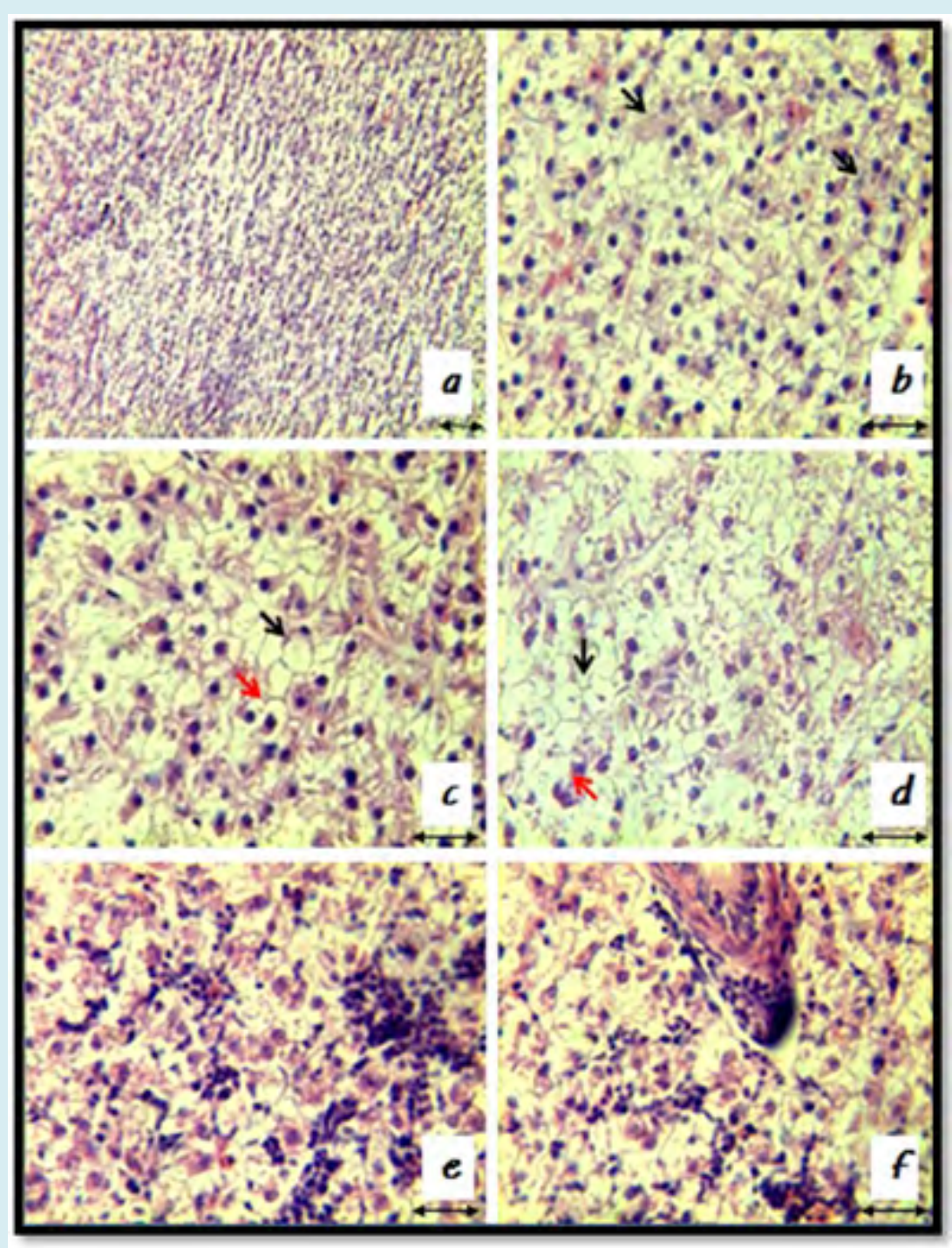

Figure 2: Histological biomarkers in liver of Aristichthys nobilis Rich. under the action of thiamethoxam, H\&E [19]. a: Normal histological structure, $\mathrm{x} 200$

b: Granular degeneration at a concentration of $6.6 \mathrm{mg} / \mathrm{L}$ thiamethoxam, $\mathrm{x} 400$

c: Cacuolar and fatty degeneration at a concentration of $10 \mathrm{mg} / \mathrm{L}$ thiamethoxam, $\mathrm{x} 400$

$\mathrm{d}$ : Necrobiotic changes at a concentration of $20 \mathrm{mg} / \mathrm{L}$ thiamethoxam, $\mathrm{x} 400$

e: Lymphocytic proliferation at a concentration of $20 \mathrm{mg} / \mathrm{L}$ thiamethoxam, $\mathrm{x} 400$

f: Hyperemia at a concentration of $20 \mathrm{mg} / \mathrm{L}$ thiamethoxam, $\mathrm{x} 400$

\section{Conclusion}

In order to make a comprehensive assessment reflecting the effects of organic pollutants, such as pesticides in aquatic ecosystems, monitoring only one biomarker in fish is not sufficient enough [20-22]. A complex assessment is required, including both tissue changes and changes in enzyme activity. It is also necessary to compare the effect of priority organic pollutants, both in the laboratory and in the field. Applied concentrations, exposure time, and species sensitivity play an important role in determining the extent of changes in the fish body. On the basis of a comparison of these factors, a model for assessing the pollution of aquatic ecosystems with priority organic pollutants included in Directive 2013/39/ EU can be built $[23,24]$. This model can be applied both, in agricultural practices and ecological monitoring in order to prepare an adequate regulatory framework, which includes assessment of changes in biota, such as fish. 


\section{Acknowledgement}

We thank the Ministry for Education and Science, Bulgaria and The Scientific Research Fund for the financial support of project M26/6 (Scientific Fundamental Research for Young Scientists and Postdocs).

\section{References}

1. De Castilhos Ghisi N (2012) Pesticides-Advances in Chemical and Botanical Pesticides. In: Relationship between Biomarkers and Pesticide Exposure in Fishes: A Review.

2. Bernet D, Schmidt H, Meier W, Burkhardt Holm P, Wahli T (1999) Histopathology in fish: a proposal for a protocol to assess aquatic pollution. Journal of Fish Diseases 22(1): 25-34.

3. Paithane KT, Sonawane DL, Bhandare RY, More PR (2012) Histophatological changes due to induced dimethoate in the liver of freshwater fish Channa punctatus from river Shivana, Aurangabad (MS) India. The Ecoscan S1: 213217.

4. Peebua P, Kruatrachue M, Pokethitiyook P, Kosiyachinda $P$ (2006) Histological effects of contaminated sediments in Mae Klong River Tributaries, Thailand, on Nile tilapia, Oreochromis niloticus. Science Asia 32: 143-150.

5. Costa PM, Caeiro S, Lobo J, Martins M, Ferreira AM, et al. (2011) Estuarine ecological risk based on hepatic histopathological indices from laboratory and in situ tested fish. Marine Pollution Bulletin 62(1): 55-65.

6. Singh RN (2014) Effects of dimethoate (EC 30\%) on gill morphology, oxygen consumption and serum electrolyte levels of Common Carp, Cyprinus Carpio (Linn). International Journal of Scientific Research in Environmental Sciences 2(6): 192-198.

7. Mohamed FAS (2009) Histopathological studies on Tilapia zillii and Solea vulgaris from Lake Qarun, Egypt. World Journal of Fish and Marine Sciences 1(1): 29-39.

8. Van der Oost R, Beyer J, Vermeulen NPE (2003) Fish bioaccumulation and biomarkers in environmental risk assessment: A review. Environmental Toxicology and Pharmacology 13(2): 57-149.

9. Stoyanova S, Yancheva V, Velcheva I, Uchikova E, Georgieva E (2015b) Histological alterations in common carp (Cyprinus carpio Linnaeus, 1758) gills as potential biomarkers for fungicide contamination. Brazilian Archives of Biology and Technology 58(5): 757-764.
10. Yancheva V, Stoyanova S, Velcheva I, Georgieva E (2016) Histological responses in common carp (Cyprinus carpio L.) and common rudd (Scardinius erythrophatalamus L.) from Topolnitsa reservoir, Bulgaria. Acta Zoologica Bulgarica 68(1): 103-109.

11. Stoyanova S, Yancheva V, Velcheva I, Mollov I, Todorova $\mathrm{K}$, et al. (2018) Glyphosate-based herbicide alters the histological structure of gills of two economically important cyprinid species (Common carp, Cyprinus carpio and Bighead carp, Aristichthys nobilis). Applied Ecology and Environmental Research 16(3): 2295-2305.

12. Georgieva E, Stoyanova S, Velcheva I, Vasileva T, Bivolarski $\mathrm{V}$, et al. (2014b) Metal effects on histological and biochemical parameters of common rudd (Scardinius erythrophthalmus L.). Archives of Polish Fisheries 22(3): 197-206.

13. Stoyanova S, Yancheva V, Velcheva I, Georgieva E (2015a) Thiamethoxam causes histochemical changes in the liver of Aristichthys nobilis Rich., 1845. Journal of Bioscience and Biotechnology 4(3): 321-325.

14. Georgieva E, Atanasova P, Velcheva I, Stoyanova S, Yancheva V (2013) Histochemical effects of "Verita WG" on glycogen and lipid storage in common carp (Cyprinus carpio L.) liver. Ecologia Balkanica 5(2): 91-97.

15. Stoyanova S, Georgieva E, Velcheva I, Yancheva V (2013) Effects of the insecticide "Actara 25 WG" on the glyconeogenesis in the liver of common carp (Cyprinus carpio L.). Journal of Bioscience and Biotechnology 1(3): 249-254.

16. Yancheva V, Velcheva I, Georgieva E, Stoyanova S (2019) Periodic Acid-Schiff (PAS) reaction in fish liver exposed to fungicide contamination: A possible histochemical biomarker. Ecologia Balkanica 11(1): 1-10.

17. Stoyanova S, Georgieva E, Velcheva I, Atanassova P, Yancheva V (2019) Lipid accumulation in Cyprinus carpio (Linnaeus, 1785) liver induced by thiamethoxam. Zoonotes 1: 4.

18. Georgieva E, Stoyanova S, Velcheva I, Yancheva V (2014) Histopathological alterations in common carp (Cyprinus carpio L.) gills caused by thiamethoxam. Brazilian Archives of Biology and Technology 57(6): 991-996.

19. Stoyanova S, Yancheva V, Iliev I, Vasileva T, Bivolarski V, et al. (2016) Biochemical, histological and histochemical changes in Aristichthys nobilis Rich. liver exposed to thiamethoxam. Periodicum Biologorum 118(1): 29-36.

20. (2013) Directive 2013/39/EU of European Parliament 
and of the Council amending Directives 2000/60/EC and $2008 / 105 / \mathrm{EC}$ as regards priority substances in the field of water policy. Official Journal of the European Union.

21. Mladenova R, Neykova A (2008) Gas chromatographic determination of pesticide residues in surface water. Union of Scientist, Stara Zagora, International Scientific Conference pp: 8.

22. Singh B, Mandal K (2013) Environmental impact of pesticides belonging to newer chemistry. In: Dhawan AK, Singh B, Brar Bhullar M, Arora R, et al. (Eds.), Integrated pest management. Scientific Publishers, Jodhpur, India, pp: 152-190.

23. Yancheva V, Velcheva I, Stoyanova S, Iliev I, Vasileva, et al. (2016b) Toxicity of two organophosphorous pesticides on Bighead carp (Aristichthys nobilis Richardson, 1845) liver. Applied Ecology and Environmental Research,14(1): 397-410.

24. Yancheva V, Velcheva I, Stoyanova S, Georgieva E (2016c) Histological biomarkers in fish as a tool in ecological risk assessment and monitoring programs: a review. Applied Ecology and Environmental Research 14(1): 47-75. 